\title{
Nutritional Status and Breast Feeding Practice among Mothers Attending Lactation Management Centre
}

\author{
Saria Tasnim ${ }^{1}$, Syeda Nazia Akhtar ${ }^{2}$ and F M Anamul Haque ${ }^{2}$ \\ ${ }^{1}$ Department of Obs \& Gynae. Institute of Child and Mother Health, Dhaka, Bangladesh \\ ${ }^{2}$ Institute of Child and Mother Health, Dhaka, Bangladesh
}

Correspondence should be addressed to: Saria Tasnim; sariatasnim2007@gmail.com

Received Date: 2 November 2013; Accepted Date: 12 January 2014; Published Date: 31 March 2014

Academic Editor: Yuichiro Yamashiro

Copyright (C) 2014 Saria Tasnim, Syeda Nazia Akhtar and F M Anamul Haque. Distributed under Creative Commons CC-BY 3.0

\begin{abstract}
Breast feeding is universally practiced in Bangladesh however, the recommended practice of exclusive breast feeding for 6 months is not followed optimally.

Motivation-The purpose of this study was to assess nutritional status of mothers attending the lactation management centre, and to find out their breast feeding practices and the reason for attending lactation management centre.

Design-This was a cross sectional study conducted at the institute of Child and Mother Health (ICMH) from March to April 2012 among the mothers attending lactation management centre. Data were collected using structured questionnaire.

Findings-A total 106 mothers were interviewed. Among them $8.3 \%$ were adolescents. Most of the infants were below 6 month old, and $58.7 \%$ were $\leq 30$ days old. Exclusive breast feeding was reported by $52 \%$. Regarding the type of feeding in the last 24 hours, $60 \%$ received only breast milk $32.4 \%$ and had breast feeding and artificial milk, and only $2.9 \%$ received complementary feeding ĕ Breast feeding. The main reason for attending LMC was not enough milk (25\%), breast problem (26\%) and $21.2 \%$ stated lack of knowledge. About $70.9 \%$ had average body build, and only $4.9 \%$ have a body mass index $<18.5$. There was no relation between body mass index of the mother and the exclusive breast feeding. Exclusively, breastfeeding was more among mothers who took antenatal care in last pregnancy.

Implication-Lactation problems are more likely in the first month of the baby, and feeling of insufficient milk in the breast is a major threat to sustenance of exclusive breast feeding. Maternal nutritional status does not relate with breast feeding practices.
\end{abstract}

Keywords: Exclusive breast feeding, nutritional status, breast feeding practice. 


\section{Introduction}

Breast feeding is a common practice in Bangladesh. Ninety eight percent of children are breast fed at some time. However, the recommended practice of exclusive breast feeding for 6 months is not followed optimally (BDHS, 2009). The trend of EBF, as evidenced through Bangladesh demographic and health survey (BDHS), shows more or less static figure through 1993 to 2007 and it was $46 \%, 42 \%$ and $43 \%$, respectively (BDHS, 1995, BDHS, 2005, BDHS., 2009) and there has been marked improvement to $64 \%$ in 2011 (BDHS, 2011).

The global picture of breast feeding practice shows that exclusive breastfeeding rates are low, at about 25\% in Africa, 45\% in Asia and $31 \%$ in Latin America and the Caribbean (Lauer J A, 2004). The prevalence of continued breastfeeding is about $86 \%$ for infants 6-11 months of age in the developing world and for children 12-23 months of age, it is about $37 \%$ in Latin America, in the Caribbean $70 \%$ and $72 \%$ in Africa and Asia (Lauer J A, 2004).

The prevalence and duration of breastfeeding are recognized as important health indicators (WHO, 2001). Bangladesh is one of the few countries where most of the mothers follow the Innocenti Declarations ideal of breastfeeding for "two years and beyond". Giasuddin, et al. reported median duration of full breast-feeding is 3.67 months, and mean and median durations of total breast-feeding are 31.3 and 30 months, respectively (Giasuddin, 2004). National survey shows the mean duration of EBF was 3.3 month, and the median duration of total breast feeding 32.8 months (BDHS, 2009).In comparison to other South Asian countries like India, Pakistan and Sri Lanka where average durations of breast-feeding were $18.4,21.8$ and 23.2 months respectively, breast-feeding duration is relatively higher in Bangladesh (Rajaretnam T, 1994, Page HJ, 1992, Mahler K, 1996).
The growth and development of a child critically depends on improved feeding practices (León-Cava N, 2002). Different studies from developing countries show that the risk of nutritional deficiency and growth retardation in children is maximum between 3 and 15 months of age, because this age period is vulnerable for suboptimal breastfeeding and inadequate complementary feeding practices (Shrimpton, 2001). In Bangladesh some liquid or solid food are often given to infants too early, and study shows $6 \%$ are given solid or semisolid food under 6 months age (BDHS, 2009). On the other hand, the delay in starting complementary food is also common and only $21 \%$ of children between $6-23$ month receive an appropriate diet (BDHS, 2011).

In most of the maternity care hospitals, a lactation management centre exists to help mothers with breast feeding problems and to promote, protect and support breast feeding. There are limited data on nutritional status of lactating mothers in Bangladesh and whether maternal nutrition has any effect on breast feeding practices is not much explored. The purpose of this study was to assess the nutritional status of lactating mothers, to find out their breast feeding practices and reasons for attending the lactation management centre. This will help to address the behavioral issues for the promotion of breast feeding practices in the context of Bangladesh.

\section{Method}

This was a cross sectional study conducted at the Institute of Child Mother Health during March-April 2012. The mothers attending lactation management centre were selected consecutively. Data were collected using structured questionnaire and analyzed in SPSS program. 


\section{Results}

Among a total 106 mothers, 8.6\% were adolescents, $61.9 \%$ belong to $20-25$ yrs, and mean age was $23.9 \pm 4 y$ rs. Most of the infants were below 6 months of age and 58.7\% were $\leq 30$ days old (Table-1). Exclusively, breast feeding was reported by 52\% (Figure-1) Regarding the type of feeding in last 24 hours, $60 \%$ received only breast milk, $32.4 \%$ had BF and Artificial milk, and only 2.9\% received CF ě Breast feeding (Table-2). The main reason for attending LMC was not enough milk (25\%), breast problem (26\%) and $21.2 \%$ stated lack of knowledge (Table3) About $70.9 \%$ had average body build, and only $4.9 \%$ have a BMI < 18.5 (Table-4). There was no relation between the BMI of the mother and the EBF (Table 5) Among those who were delivered by CS, $60.3 \%$ were exclusively breastfed (Table-6). Exclusively, breastfeeding was more among mothers who took ANC in last pregnancy (Figure 2).

Table1: Distribution according to Age of Mother and Child $(n=106)$

\begin{tabular}{|c|c|c|}
\hline Age of Mother & No & $\%$ \\
\hline$<19$ & 5 & 8.3 \\
\hline $20-25$ & 37 & 61.7 \\
\hline$>25$ & 18 & 30 \\
\hline \multicolumn{3}{|c|}{ Mean 23.99 \pm 4.03 (range 17-42) } \\
\hline \multicolumn{3}{|l|}{ Age of Baby } \\
\hline$<30$ Days & 61 & 58.7 \\
\hline 31-90 days & 33 & 31.7 \\
\hline $91-180$ days & 6 & 5.7 \\
\hline$>180$ days & 4 & 3.8 \\
\hline
\end{tabular}

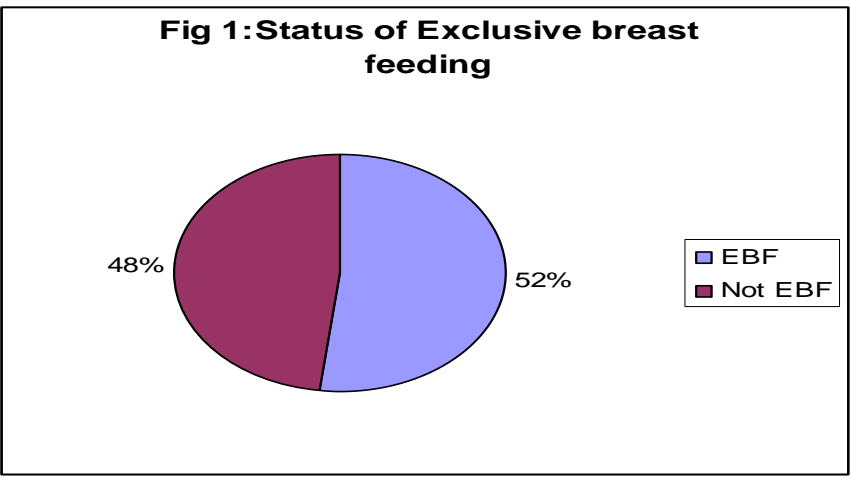

Table 2: Distribution according to Type of Feeding in Last 24 Hours

\begin{tabular}{|l|l|l|}
\hline Type of food & Number & Percentage \\
\hline Only breast milk & 63 & 60 \\
\hline Breast milk and artificial milk & 34 & 32.4 \\
\hline Only artificial milk & 5 & 4.8 \\
\hline Breast milk and complementary food & 3 & 2.9 \\
\hline
\end{tabular}


Table 3: Distribution according to Reasons for Attending LMC $(n=106)$

\begin{tabular}{|l|l|l|}
\hline Reasons for attending LMC & No & \% \\
\hline Not enough milk & 26 & 25 \\
\hline Breast problem & 27 & 26 \\
\hline Lack of knowledge & 22 & 21.2 \\
\hline Refusal to breast & 6 & 5.8 \\
\hline Relactation & 9 & 8.7 \\
\hline Others & 8 & 7.3 \\
\hline
\end{tabular}

Table 4: Nutritional Status of Mothers according to BMI and MUAC

\begin{tabular}{|l|l|l|}
\hline BMI & Number & Percentage \\
\hline$<18.5$ & 5 & 4.9 \\
\hline $18.5-22$ & 32 & 31.1 \\
\hline $22-26$ & 41 & 39.8 \\
\hline$>26$ & 25 & 24.3 \\
\hline MUAC & & \\
\hline $21-23 \mathrm{~cm}$ & 18 & 17.6 \\
\hline$>23 \mathrm{~cm}$ & 84 & 82.4 \\
\hline
\end{tabular}

Table 5: Relation between BMI and EBF under 6 Months Baby (N=97)

\begin{tabular}{|l|l|l|}
\hline & EBF No (\%) & Not EBF\% \\
\hline $\mathrm{BMI} \leq 18.5$ & $2(3.8)$ & $3(6.7)$ \\
\hline $\mathrm{BMI}>18.5$ & $50(96.2)$ & $42(93.3)$ \\
\hline
\end{tabular}

P value 0.431

Table 6: Relation between Mode of Delivery with EBF $\{n=106\}$

\begin{tabular}{|l|l|l|}
\hline Mode of delivery & EBF \% & Not EBF\% \\
\hline NVD & 50 & 50 \\
\hline CS & 58.3 & 41.7 \\
\hline
\end{tabular}




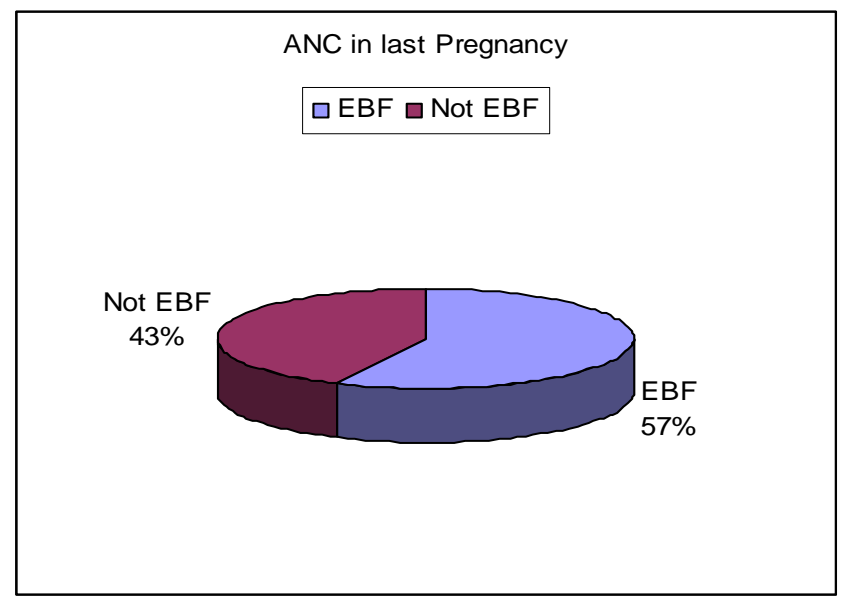

Figure 2: Relation between ANC in Last Pregnancy and EBF $(n=106)$

\section{Discussion}

The assessment of exclusive breast feeding status based on a 24-hour recall may not always represent a true picture, especially when there is chance of over reporting, as Lauer found that infants consuming water or water-based drinks along with breast milk are also classified as exclusive breast feeding (Lauer J A, 2004, Armitage, 2002). Routine feeding practices of infants may also change when ill or if the mother is not available at the time of feeding. Some community-based studies have found that infants classified as exclusively breastfeeding with 24 -hour recall receive other liquids and even solid foods on a less-than-daily basis (Armitage, 2002, Haidar, 2000). In this study, $90 \%$ were within 3 months of age but only $60 \%$ were exclusively breastfed, and this is consistent with national data (BDHS, 2011). In comparing the records of 24-hour recall and those from mothers' daily records, it was found that 24-hour recall overestimated exclusive breastfeeding rates by about $40 \%$ at both two and four months of age (Haidar, 2000).

Malnutrition is a common problem in Bangladesh. Survey shows 59\% of women (15-49 year) have normal BMI, 30\% had $<18.5$, and $12 \%$ have BMI 25 or above (BDHS, 2009). A previous study showed $34 \%$ of women had BMI $\leq 18.5$ (BDHS, 2004)The quantitative relationship between maternal nutritional status and dietary intake with the volume and composition of the mother's milk has been studied. Jelliffe, 1978 found the composition of the mother's milk of marginally nourished mothers is generally maintained within or near the range reported for well nourished women, but protein and fat concentration are influenced by maternal nutritional status and dietary intake (Boerma, 1993).

Prentice et al. found a positive relationship between maternal in triceps skin fold thickness measurement and fat concentration in Gambian women (Prentice, 1981). Hanafi et al. found a significant reduction in the concentrations and amounts of energy and protein in the milk of malnourished mothers (Hanafi, 1972). Brown et al reported that the increase in triceps skin fold thickness of mothers was associated with increases in fat and energy concentration of breast milk, and increases in body weight were associated with the increase in the amount of milk and all its major nutrients (Brown, 1986). In the current study, the majority of mothers were well nourished however, a quarter of them complained of insufficient milk production. 
One common problem for breast feeding perceived by lactating mother is low milk production. Study found 54\% lactating mothers mentioned that their babies do not get sufficient breast milk, and their complaint was more prevalent among urban than rural mothers (Akhtar, 1998). For sustenance of exclusive breast feeding in the first 3 months it is most crucial and is vulnerable to distortions due to the perception of not enough milk. A study shows that the common perception of not enough milk is the most important factor that hampers exclusive breast feeding and trigger the introduction of artificial milk (Haidar, 2010).

Breast problems were the cause for attending lactation management centre in about one fourth of the mothers. Care seeking practices of mothers attending the lactation management centre of ICMH was compared between 2000 and 2006 . It was found that breast problems were mentioned by $32.5 \%$ vs. $40 \%$ and not enough milk was complained of in $20 \%$ vs. $27.5 \%$ of mothers attending the centre during 2000 and 2006 respectively (Tasnim, 2007). In a study at Rajshahi medical college, it was found that $12 \%$ of the mothers had different types of breast problems. The most important problem was breast engorgement, next was sore nipples, flat nipple, cracked nipple and breast abscess (Hossain, 2005). The examination of breast for the identification of any problem like retracted nipple may help to prepare mothers for exclusive breast feeding. At the same time, routine examination of breast during postnatal period is mandatory to boost up maternal confidence and detect any breast problem like crack nipple, sore nipple early, and prevent complications.

Strategies for the promotion of breastfeeding include a combination of factors like hospital norms and services, legislation and institutional policies, health worker training, mass media campaigns, peer counseling and education, and mother-to-mother support groups (Green, 1999, Hill, 2004). Support for breast feeding during immediate postpartum period is crucial to boost up the mother's confidence and sustaining breast feeding. However, high rates of initiation of exclusive breast feeding and low sustenance often coexist. Rooming in and bedding in during hospital stay has a positive effect in sustaining exclusive breast feeding. It is often said mothers after caesarean section face more difficulty in early initiation and exclusive breast feeding because of pain and other problems. However, they can successfully initiate breast feeding soon after operation and can room in with their infants if proper support is given. The current study found that EBF was more among mothers who underwent caesarean section. This might be the effect of hospital policy in accordance with baby friendly hospital.

Access to information and motivation on BF during prenatal period is an important predictor of postnatal successful lactation performance. Community based behavior change programs focusing on hospital norms and services, legislation and institutional policies, health worker training, mass media campaigns, peer counseling and education, mother to mother support and a combination of these strategies has shown marked increases in exclusive breastfeeding of infants 0 to 6 months in different countries of Africa (Quinn, 2005). Although antenatal care was received by most of the mothers in this study exclusive breast feeding was not optimum indicating some gaps in the counseling, and there should be more emphasis on this issue.

\section{Conclusion}

Lactation problems are more likely in the first month of the baby and the feeling of insufficient milk in the breast is a major threat to sustenance of exclusive breast feeding.

About one fifth of mothers perceived to have lack of knowledge which indicates people's concern for breast feeding. Maternal nutritional status does not relate with breast feeding practices. Exclusive breast feeding 
was more among those delivered by caesarean section, probably due to greater contact with health care providers and their active support.

\section{References}

Akhter, H. H., Akhter, M. \& Azad, K. M. (1998). "A National Baseline Survey to Assess the Breastfeeding Practices in Bangladesh," BIRPERHT.

Armitage, P., Berry, G. \& Matthews, J. N. S. (2002). "Modelling Categorical Data," In Statistical Methods in Medical Research, 4th edition, Oxford, England: Blackwell; 485-502.

Bangladesh Demographic and Health survey 1993-94. (1995). 'Extended Analysis. National Institute of Population Research and Training,' Mitra and associates.

Bangladesh Demographic and Health survey (2011). "National Institute of Population Research and Training," Mitra and associates.

BDHS (2001). "Bangladesh Demographic and Health Survey 1999-2000," National Institute of Population Research and Training, Mitra and associates.

BDHS (2005). 'Bangladesh Demographic and Health Survey 2004,' National Institute of Population Research and Training, Mitra and associates.

BDHS. (2009). 'Bangladesh Demographic and Health Survey 2007,' National Institute of Population Research and Training (NIPORT). Mitra \& associates.

Boerma, J. T. \& Sommerfelt, A. E. (1993). 'An Assessment of the Quality of Breast-Feeding Data in DHS-I Surveys,' Calverton, Maryland, USA: Macro International.

Brown, K. H., Akhtar, N. A., Robertson, A. D. \& Ahmed, M. G. (1986). "Lactational Capacity of Marginally Nourished Mothers: Relationships between Maternal Nutritional Status and
Quantity and Proximate Composition of Milk," Pediatrics, 78: 909

Giashuddin, M. S. \& Kabir, M. (2004). "Duration of Breast-Feeding in Bangladesh," Indian Journal of Medical Research; 119: 267272

Green, C. P. (1999). "Improving Breastfeeding Behaviors: Evidence from Two Decades of Intervention Research," Published for USAID by the LINKAGES Project, Washington, DC;

Haider, R., Ashworth, A., Kabir, I. \& Huttly, S. R. A. (2000). "Effect of Community-Based Peer Counselors on Exclusive Breastfeeding Practices in Dhaka, Bangladesh: A Randomized Controlled Trial," Lancet, 356:1643-1647. PubMed Abstract | Publisher Full Text

Haider, R., Rasheed, S., Sangvi, T. G., Hassan, N., Pachon, H., Islam, S. \& Jalal, C. S. B. (2010). "Breastfeeding in Infancy: Identifying the Program-Relevant Issues in Bangladesh," International Breastfeeding Journal; 5:21-32

Hanafy, M. M., Morsey, M. R. A., Seddick, Y., Habib, Y. A. \& El Lozy, M. (1972). "Maternal Nutrition and Lactation Performance," Journal of Tropical Pediatrics; 18:187-191

Hill, Z., Kirkwood, B. \& Edmond, K. (2004). "Family and Community Practices that Promote Child Survival, Growth and Development: A Review of the Evidence," Geneva, Switzerland: World Health Organization;

Hossain, M. A., Haque, M. I., Siddiqui, A. B. \& Bari, M. I. (2005). "Activities of Lactation Management Centre of Rajshahi," Journal of Teachers Association, December; 18 (2)

Jelliffe, D. B. \& Jelliffe, E. F. P. (1978). Human Milk in the Modern World, Oxford, Oxford University Press, 
Lauer, J. A., Betrán, A. P., Victora, C. G., de Onís, M. \& Barros, A. J. D. (2004). "Breastfeeding Patterns and Exposure to Suboptimal Breastfeeding among Children in Developing Countries: Review and Analysis of Nationally Representative Surveys," $B M C$ Medicine 2:26 doi:10.1186/1741-7015-2-26

León-Cava, N., Lutter, C., Ross, J. \& Martin, L. (2002). Quantifying the Benefits of Breastfeeding: A Summary of the Evidence, Published by PAHO and by the LINKAGES Project for USAID, Washington, DC;

Mahler, K. (1996). "Women Breast-Feeding Infants Longer in Many Developing Countries," International Family Planning Perspectives 22: 134-5.

Page, H. J., Lesthaeghe, R. J. \& Shah, I. H. (1982). "Illustrative Analysis: Breastfeeding in Pakistan," WFS Scientific Reports No. 37. Voorburg, Netherlands: International Statistical Institute; 115.

Prentice, A., Prentice, A. M. \& Whitehead, R. G. (1981). "Breast-Milk Fat Concentrations of Rural African Women: 2 Long Time Variations within a Community," British Journal of Nutrition; 45: 495-503
Quinn, V. J., Guyon, A. B., Schubert, J. W., Stone-Jiménez, M., Hainsworth, M. D. \& Martin, L. H. (2005). "Improving Breastfeeding Practices on a Broad Scale at the Community Level: Success Stories From Africa and Latin America," Journal of Human Lactation 21(3).

Rajaretnam, T. (1994). 'Trend and Differentials in Breast-Feeding and Amenorrhea Durations in a Rural Area in south India,' Demography India 23: 83-95.

Shrimpton, R., Victora, C. G., de Onis, M., Costa Lima, R., Blössner, M. \& Clugston, G. (2001). "Worldwide Timing of Growth Faltering: Implications for Nutritional Interventions," Pediatrics. 2001; 107:E75.

Tasnim, S. \& Banu, L. P. (2007). 'Care Seeking for Breast Feeding in a Periurban Hospital,' Bangladesh Medical Journal; 36 (1): 4-6

WHO (2001). 'Resolution WHA54.2: Infant and Young Child Nutrition (WHA54.2) Geneva,' Switzerland: World Health Organization. 